\title{
Estudio tafonómico e interpretación del gesto funerario de los restos óseos de la Cova de Montanissell (Alt Urgell, Lleida)
}

\author{
Taphonomic study of the human remains from Cova de Montanissell (Alt Urgell, Lleida) \\ and interpretation of the funerary gesture
}

Núria Armentano (*)
Xavier Jordana (**)
Assumpcio Malgosa (*)

\section{RESUMEN}

La tafonomía ofrece un marco teórico y metodológico para comprender la transición desde la muerte de los organismos hasta su hallazgo. Así ayuda a interpretar el gesto funerario de las sociedades del pasado. Este trabajo analiza los efectos tafonómicos, observados in situ y en el laboratorio, de los restos humanos procedentes de la Cova de Montanissell (Lleida), en el noreste de la Península Ibérica, en relación con los resultados paleogenéticos, paleopatológicos y radiocarbónicos. La cavidad fue utilizada por una comunidad de la Edad del Bronce para enterrar 8 individuos en sucesivas inhumaciones de carácter primario. La interacción de agentes y procesos tafonómicos sobre los esqueletos condujeron a una historia compleja pero de baja intensidad, que ha permitido una muy buena preservación del tejido óseo. La integración de los resultados procedentes de las diferentes líneas de investigación ha sido fundamental para discutir sobre la intencionalidad o no de los entierros, de la disposición de los individuos, y su relación de parentesco.
(*) Grup de Recerca en Osteobiografia (GROB), Unitat d'Antropologia Biològica, Facultat de Biociències, Universitat Autònoma de Barcelona, Edifici C, Campus de Bellaterra. 08193 Cerdanyola del Vallès. Barcelona. España.

Correos e.: armentano.nuria@gmail.com; assumpcio.malgosa@uab.cat

(**) Institut Català de Paleontologia Miquel Crusafont, Universitat Autònoma de Barcelona, Edifici ICP, Campus de Bellaterra. 08193 Cerdanyola del Vallès. Barcelona. España. Correo e.: xavier.jordana@icp.cat

Recibido 20-X1-2012; aceptado 9-IV-2013.

\begin{abstract}
Taphonomy aims to provide a theoretical and methodological frame to understand the transition of biological remains from the moment of death to their recovery, as well as to interpret the funerary gesture of the past societies. In this article, the reconstruction of the taphonomic history of the human remains from Montanissell cave (Lleida) is presented, using the analysis of the taphonomic effects observed in situ and in the laborato$r y$, and linking them to the radiocarbon, paleogenetic and pateopathological results. The Montanissell cave was used by a Bronze Age community to bury 8 individuals. It is characterized by being a collective funerary cavity, with primary successive inhumations. The interaction of some taphonomic processes and agents on human bones leaded to a complex and of low intensity taphonomic history which allowed an exceptional preservation of the bony tissue. The combination of different investigation lines has been fundamental for the discussion about the intentional or non-intentional position of the bodies, the simultaneity or non simultaneity of the burials, and the kinship among them.
\end{abstract}

Palabras claves: Arqueología de la Muerte; Sepultura colectiva; Prehistoria reciente; Antropología física; Paleopatología.

Key words: Death Archaeology; Collective Burial; Recent Prehistory; Physical Anthropology; Paleopathology.

\section{INTRODUCCIÓN}

La excavación de depósitos funerarios es frecuente y tradicional en la disciplina arqueológica 
para la que su diversidad es uno de los más preciados objetos de estudio. Sin embargo pocas veces se incluye el análisis tafonómico de los restos antropológicos como vehículo para la interpretación del gesto funerario en el pasado. Etimológicamente "tafonomía" procede del griego

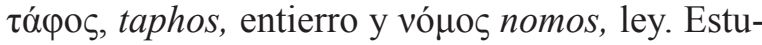
dia los procesos químicos, físicos y biológicos que sufren los cadáveres durante la transición de los organismos desde la muerte hasta su hallazgo. En antropología biológica y forense abarca todo lo relacionado con la descomposición, transformación, manipulación, conservación, transporte, desgaste y cualquier alteración de los restos humanos, desde su muerte hasta su completa desintegración o conservación, ya sea natural o artificial, o hasta su fosilización (Shipman 1981; Reverte 1991; Lyman 1994). La tafonomía, por lo tanto, sistematiza la información y ofrece un marco metodológico para comprender los sucesos acaecidos desde la muerte del individuo hasta su hallazgo. El desarrollo de trabajos con esta orientación ha permitido entablar un debate en torno a la tafonomía como vehículo para interpretar las

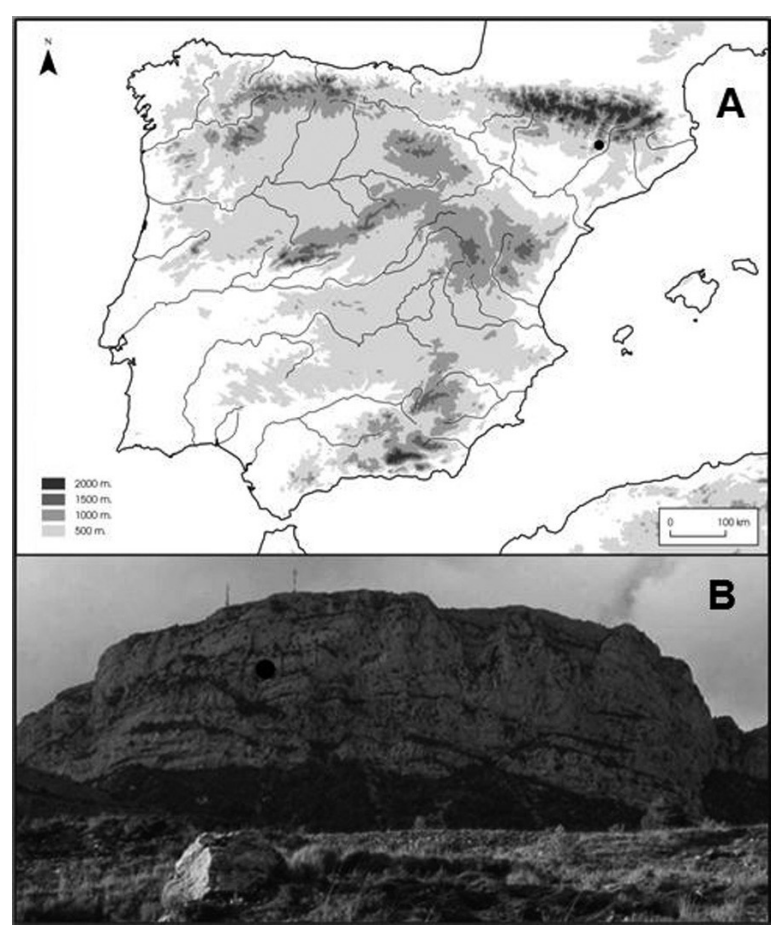

Fig. 1. La Cova de Montanissell (Alt Urgell, Lleida). A. Situación geográfica de la cueva en el Pre-pirineo Catalán y la Península Ibérica; B. Imagen de la localización de la cueva en la Serra de Boumort a 1557 m.s.n.m. prácticas funerarias y el tratamiento de la muerte en el pasado.

El presente trabajo evalúa los procesos tafonómicos ocurridos en el conjunto antropológico de La Cova de Montanissell a partir de la identificación in situ y en el laboratorio de los efectos tafonómicos macroscópicos que presentan los restos, distinguiéndolos de las eventuales alteraciones patológicas. La identificación y sistematización de tales efectos tiene el fin de interpretar el tratamiento de los miembros de esta comunidad prehistórica tras su muerte. Esta cavidad, de difícil acceso y cerrada, se empleó para un entierro colectivo que estuvo preservado sin apenas alteraciones hasta su descubrimiento el año 2004 (López et al. 2005).

La cavidad forma parte de un complejo kárstico de más de 2 millones de años de antigüedad situado en la Sierra de Sant Joan de Montanissell, paralela a la Sierra de Boumort, en el Pre-pirineo catalán. Se abre en la cara sur de la sierra, en el término municipal de Sallent, a 1557 m.s.n.m. (Fig. 1). Se desconoce el acceso original al espacio donde se efectuaron los entierros durante la Edad del Bronce: una cubeta recóndita a $28 \mathrm{~m}$ de profundidad que ocupaba unos $20 \mathrm{~m}^{2}$. La cubeta es una "habitación funeraria" delimitada de forma natural por un caos de grandes bloques desprendidos del techo de la galería en tiempos previos a la frecuentación humana (Armentano et al. 2006).

La inaccesibilidad del lugar es indiscutible. Sin embargo se hallaron los restos de tres ovicápridos articulados (F3, F4.1 y F4.2), fechados entre el 370 ANE y el 530 DNE, que probablemente murieron de inanición en los rincones cercanos a la cámara sepulcral. Estos animales, así como las visitas incontroladas posteriores al descubrimiento, son factores a tener en cuenta para interpretar correctamente la posición y el estado de los restos humanos (Armentano et al. 2008: 58).

Los elementos de cultura material sitúan el periodo de uso de la cavidad como sepulcro entorno a la Edad del Bronce medio: la base fragmentada de un vaso cerámico polípodo a mano, una aguja de hueso, cuentas de dentalia, cuentas tubulares de bronce, dos brazaletes en espiral y una diadema de bronce. También se ofrendan partes anatómicas de caprinos. Según las fechas absolutas el sepulcro se usó entre el 3200 y el 3300 BP (Armentano et al. 2008: 67). 
El entierro comprende 8 individuos: un hombre y una mujer acompañados por 6 subadultos (Fig. 2). Sus restos tenían buena conservación y consistencia y un alto grado de conexión anatómica. El conjunto sugiere una familia nuclear pero el análisis genético indica que los individuos corresponden a un mínimo de 5 linajes mitocondriales distintos, es decir, sin relación materna (Simón et al. 2011).

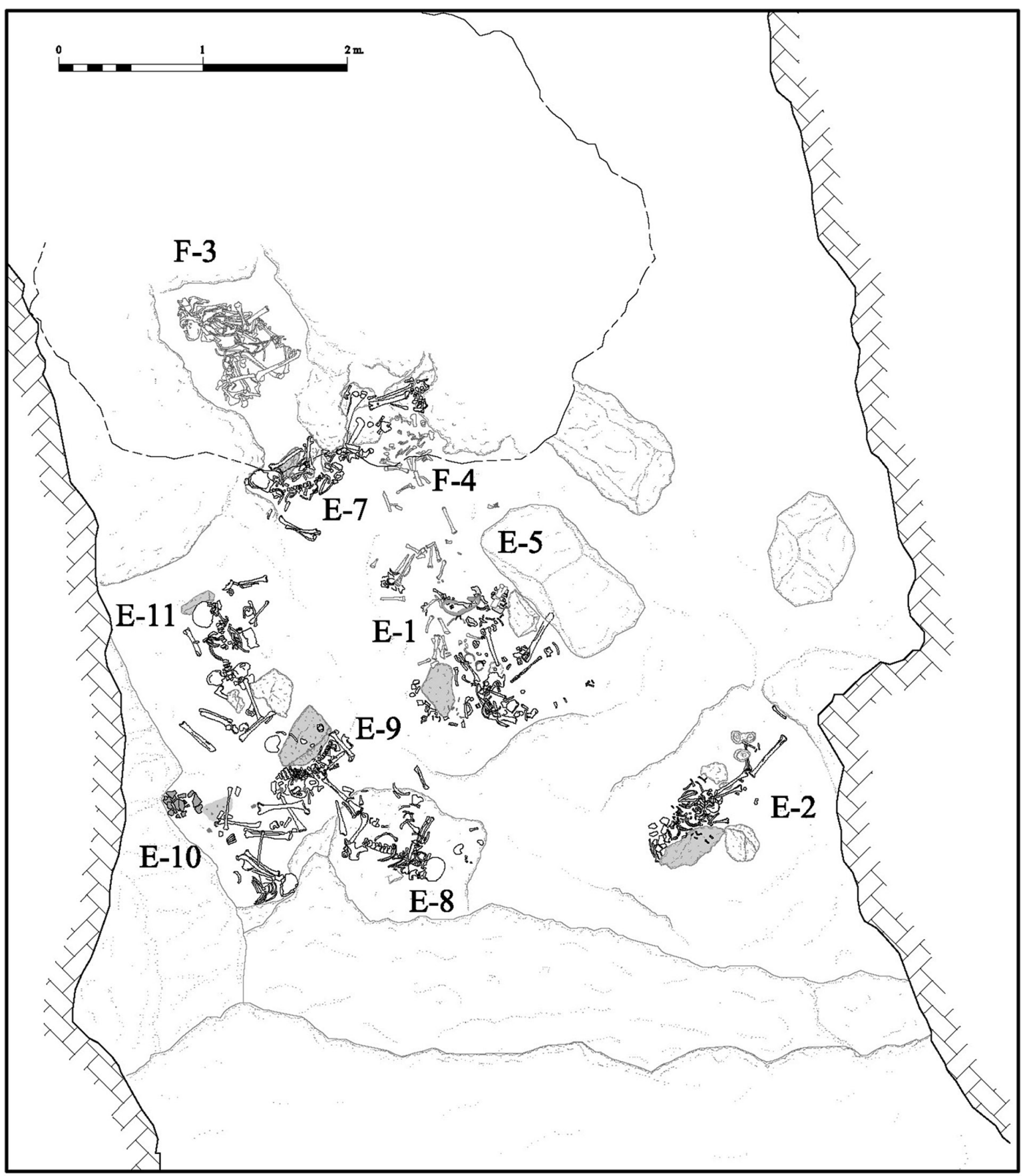

Fig. 2. Cova de Montanissell (Alt Urgell, Lleida): planta del espacio funerario utilizado durante la Edad del Bronce Medio con los restos esqueléticos de un hombre, una mujer e individuos subadultos, todos ellos muy cercanos a un bloque de piedra. La trama indica la delimitación natural del espacio de inhumaciones (dibujo Josep M. Puche).

Trab. prehist., 71, N. ${ }^{\circ} 1$, enero-junio 2014, pp. 156-172, ISSN: 0082-5638 doi: $10.3989 /$ tp.2014.12130 
El análisis detallado de la posición de cada individuo, del tipo de conexiones anatómicas, del estado de la superficie cortical de los huesos y de sus fracturas se presentan como efectos tafonómicos claves. El estudio de los restos humanos regresa como elemento fundamental para la interpretación de la práctica funeraria y la reconstrucción de la historia tafonómica del conjunto (Duday et al. 1990).

\section{MARCO TEÓRICO Y METODOLÓGICO}

La reconstrucción tafonómica del grupo humano de la Cova de Montanissell se ha basado en el análisis secuencial de las alteraciones macroscópicas de los restos esqueléticos en diferentes eventos tafonómicos. Dicha reconstrucción es necesaria, y previa, a cualquier análisis microscópico. Los "agentes tafonómicos" son la causa física de la modificación producida a un hueso o conjunto óseo, los "procesos tafonómicos" la acción de un agente y los "efectos tafonómicos" el resultado de la alteración sufrida por el hueso o conjunto óseo (Johnson 1985; Gifford-González 1991; Lyman 1994; Nawrocki 1995; Aguirre 1997; Armentano et al. 2012).

Antes del análisis tafonómico, se detalló la posición de cada individuo respecto al espacio sepulcral y a los otros esqueletos (Brothwell 1987; Duday 2009). También se calcularon los índices de preservación (IP) esquelética (Walker et al. 1988; Armentano et al. 2012) que establecen la preservación de determinadas agrupaciones óseas -sin considerar su conservación-, en función de la ecuación: $\mathrm{IPn}=\Sigma$ (elementos preservados) $/ \Sigma$ (elementos considerados) x 100. El IP considera 22 elementos: 12 de las extremidades (húmeros, radios, cúbitos, fémures, tibias y peronés), los huesos de las cinturas (escápulas, clavículas, coxales y sacro) y las tres regiones craneales (neurocráneo, esplacnocráneo y mandíbula).

Los diagnósticos de edad y sexo siguieron las recomendaciones clásicas (Ferembach et al. 1980; Krogman e Isçan 1986; Ubelaker 1989). Para la edad de los subadultos se tuvieron en cuenta principalmente la erupción de piezas dentales y su grado de desarrollo (Cretot 1978; Ubelaker 1989), así como el grado de maduración y crecimiento de los elementos óseos (Alduc-Le
Bagouse 1988; Scheuer y Black 2000). En los individuos adultos, se priorizaron los cambios en la sínfisis púbica y en la superficie auricular del coxal (Todd 1920; McKern y Stewart 1957; Gilbert y McKern 1973; Lovejoy et al. 1985). Secundariamente también se utilizaron los criterios basados en los cambios morfológicos en el extremo esternal de la cuarta costilla (Isçan et al. 1984; Krogman e Isçan 1986), el grado de desgaste de las piezas dentales (Brothwell 1987), y el grado de sinostosis de las suturas craneales (Vallois 1960). Para el diagnóstico sexual de los esqueletos subadultos se han considerado las características morfológicas de cráneo, mandíbula y hueso coxal (Krogman e Isçan 1986; Schutkowski 1993; Scheuer y Black 2000). A nivel genético se analizó el gen de la amelogenina y el SRY (Simón et al. 2011). La estatura se estimó a partir de las fórmulas de Trotter y Glesser (1952) y Pearson (Olivier 1960).

El análisis tafonómico considera tres formas de alteraciones tafonómicas macroscópicas (Armentano et al. 2012):

a) Cambios físicos y químicos observables en la superficie cortical del hueso que modifican su morfología normal como fisuras, grietas, erosiones, descamaciones, exfoliaciones, acción de las raíces, perforación por la acción de carnívoros y roedores, manchas, alteraciones del color, etc. (Behrensmeyer 1978). Deben ser reconocidas y distinguidas claramente de las eventuales patologías esqueléticas.

b) Fracturas óseas: presencia o ausencia de las mismas, forma y tipología. El patrón de rotura establece su naturaleza peri mortem o post mortem (Sauer 1998; Walker 2001; Kanz y Grossschmidt 2006; Tung 2007). Pueden ser fracturas limpias, con márgenes bien delimitados, fácilmente reconstruibles en el laboratorio, o resultar irreconocibles, cuando el registro está muy fracturado. La presión secular de la tierra, las raíces de la vegetación cercana o la eventual actividad de carnívoros pueden deformar y fracturar los esqueletos pero, a menudo, una actividad continuada en la zona es la causa principal de sus fracturas post mortem.

c) Alteraciones que afectan la distribución espacial original de los elementos esqueléticos: continuidad articular o no de los elementos y tipología de la articulación (estricta o laxa). Es preciso evaluar si la desarticulación anatómica se debe a posibles movimientos durante la descom- 


\begin{tabular}{|c|c|c|c|c|}
\hline Individuo & $\begin{array}{c}\text { Sexo determinado morfológica } \\
\text { y genéticamente* }\end{array}$ & Edad & Dataciones & Laboratorio \\
\hline E 1 & Femenino & $40-45$ & $3180 \pm 40 \mathrm{BP}$ & Beta-213102 \\
\hline E 2 & Masculino & $7 \pm 1$ & $3190 \pm 40 \mathrm{BP}$ & Beta-213103 \\
\hline E 5 & Femenino & $7 \pm 1$ & $3200 \pm 40 \mathrm{BP}$ & Beta-213105 \\
\hline E 7 & Masculino & $40-50$ & $3180 \pm 40 \mathrm{BP}$ & Beta-213106 \\
\hline E 8 & Femenino & $19-21$ & $3180 \pm 40 \mathrm{BP}$ & Beta-213107 \\
\hline E 9 & Femenino & $14 \pm 1$ & $3240 \pm 40 \mathrm{BP}$ & Beta-230404 \\
\hline E 10 & Indeterminado & $10 \pm 1$ & $3260 \pm 40 \mathrm{BP}$ & Beta-230405 \\
\hline E 11 & Femenino & $12 \pm 1$ & $3140 \pm 40 \mathrm{BP}$ & Beta-213110 \\
\hline
\end{tabular}

Tab. 1. Dataciones de la Coba de Montanisell (Alt Urgell, Lleida). La caracterización del sexo viene determinada por la interpretación conjunta de los datos morfológicos y genéticos (Simón et al. 2011: 407).

posición de los tejidos blandos o a la reutilización funeraria, la ocupación sucesiva del espacio, la acción de la vegetación, animales, etc.

Una vez reconocidos los efectos tafonómicos macroscópicos, se evalúan los agentes y procesos responsables de tales alteraciones.

La recogida de datos en el campo combinó la fotografía digital y el dibujo con fichas antropológicas de registro para cada individuo, buscando documentar toda la información arqueológica, tafonómica y antropológica disponible sobre el mismo.

\section{RESULTADOS: DESCRIPCIÓN INDIVIDUALIZADA}

El material esquelético estudiado corresponde a 8 inhumaciones primarias (Armentano y Malgosa 2003), depositadas directamente sobre la superficie del suelo de la habitación funeraria, cuyo espacio ocupan de forma amplia y repartida (Fig. 2, Tab. 1). Los esqueletos estaban libres de sedimento pero los más cercanos a la pared oeste de la habitación estaban recubiertos por una capa de calcita (espeleotema) de 2-20 $\mathrm{mm}$ de grosor, que reproducía perfectamente la forma de los huesos (1) (Fig. 3A y B). La mayoría se relacionaban con grandes bloques de piedra y ajuares. $A$ priori no se observaron acciones antrópicas de épocas posteriores, ni procesos postdeposiciona-

(1) En el laboratorio de antropología se extrajo la capa calcárea de forma manual para poder observar y estudiar correctamente el material esquelético. les que hubiesen alterado de forma significativa la posición original de los cuerpos.

El entierro E1 ocupa la parte central de la habitación funeraria. Está asociado con el ajuar más notable del conjunto: 2 brazaletes de bronce en espiral a nivel de los antebrazos, 1 collar mixto de cuentas tubulares de bronce y Dentalium y 1 diadema de bronce (Figs. 3C y 4). La diadema se localizó en la parte inferior-izquierda del cuerpo. El esqueleto, articulado en parte, tenía una preservación esquelética del $100 \%$. Corresponde a una mujer adulta de 40-45 años de edad, grácil, con una estatura estimada en $154 \mathrm{~cm}$.

Como alteración cortical en las vértebras cervicales, los radios y los cúbitos aparece una coloración verdosa intensa (Fig. 3C). También hay otras compatibles con lesiones patológicas, sin correspondencia con alteraciones tafonómicas: signos de osteoartrosis leves a nivel de la columna dorsal y lumbar; una lesión compatible con una osteocondritis bilateral en la articulación proximal de la I falange medial de los pies; osteófitos bilaterales en la cara externa de las rótulas y una reacción perióstica focal en la cara interna del tercio distal de la tibia derecha. Estas lesiones pueden tener una etiología degenerativa producto de la edad avanzada del individuo o ser de origen micro-traumático. Entre las patologías estomatológicas se observaron caries en las piezas maxilares y mandibulares, procesos fistulosos en la mandíbula, y líneas de hipoplasia del esmalte dentario (Chimenos et al.1999).

Los huesos mostraban un estado de fracturación importante, en especial, en la región craneal y los huesos largos de las extremidades. La ma- 

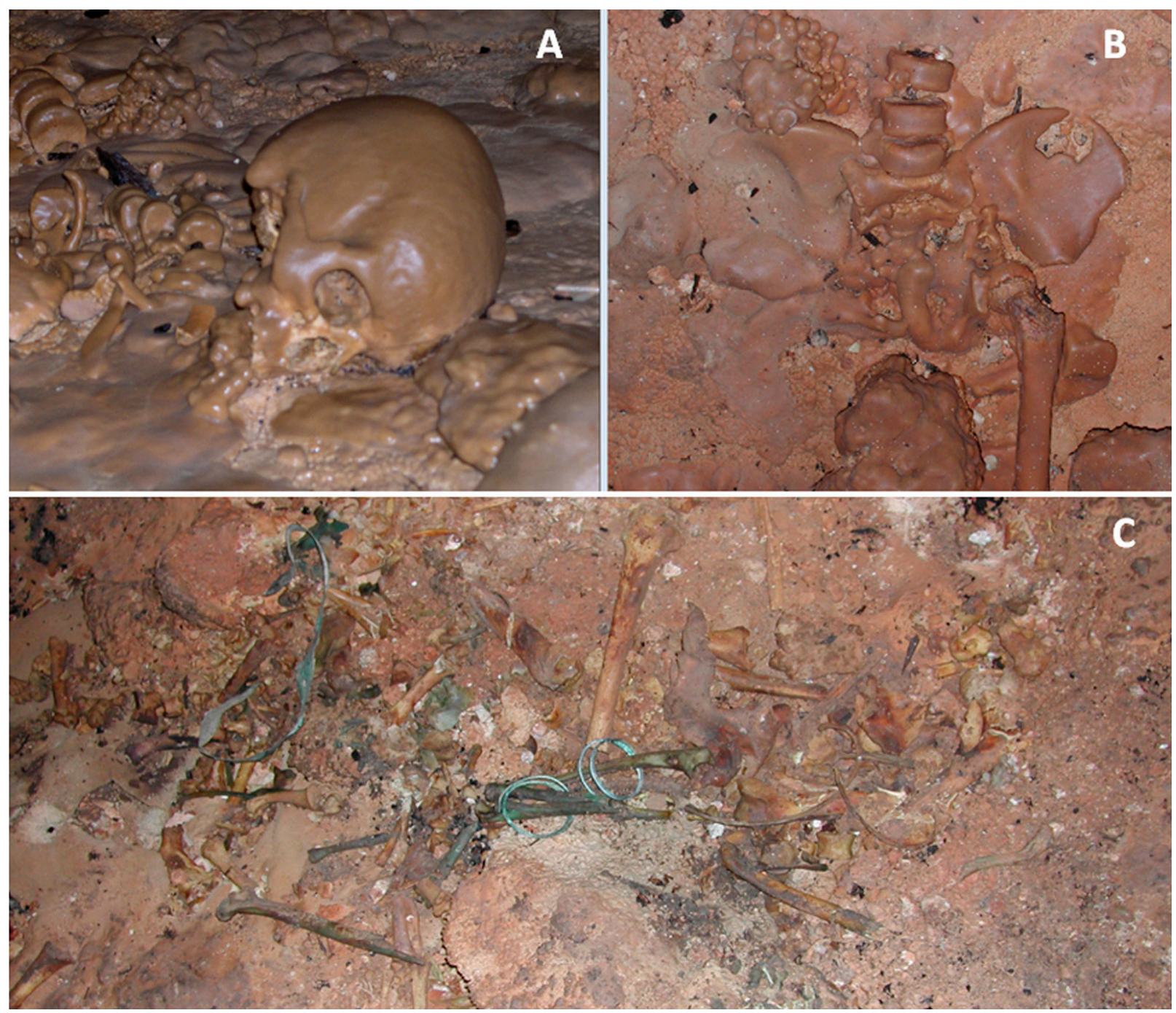

Fig. 3. Cova de Montanissell (Alt Urgell, Lleida): detalles de las inhumaciones primarias de la Edad del Bronce Medio: A. Cráneo de la niña de 12 años (E11) depositada en el extremo norte-oeste del espacio funerario; B. Cintura pélvica de la misma. Parte de los restos de los individuos quedaron completamente recubiertos por una fina capa calcárea. C. Mujer adulta (E1), depositada en la parte central de la habitación sepulcral, con un ajuar de bronce consistente en una diadema, dos brazaletes en espiral y un collar mixto de cuentas tubulares metálicas y Dentalium.

yoría son fracturas antiguas. Una es de tipo espiroidal, de trazo helicoidal (Ortner 2003; Roberts y Manchester 2005; Jordana et al. 2009) del tercio proximal de la diáfisis de húmero derecho (Fig. 5). Es típica de caídas con intento de parar el golpe. Los márgenes de esta fractura son lisos sin signos de regeneración ósea, indicando que se produjo en hueso fresco sin tiempo para regenerarse, es decir, en un momento muy cercano a la muerte. Los dos fragmentos fracturados de húmero tienen diferente coloración, debido a la oxida- ción del metal del ajuar. Este aspecto podría indicar que su separación fue previa a la reducción esquelética del cadáver.

Los restos se encontraron en un estado de remoción importante, aunque algunos como la región cervical, los antebrazos, la extremidad inferior derecha y los elementos del pie derecho mantenían una conexión anatómica laxa. De estas conexiones se infiere que la mujer fue inhumada en decúbito lateral izquierdo, con la parte superior izquierda del cuerpo descansando sobre un 

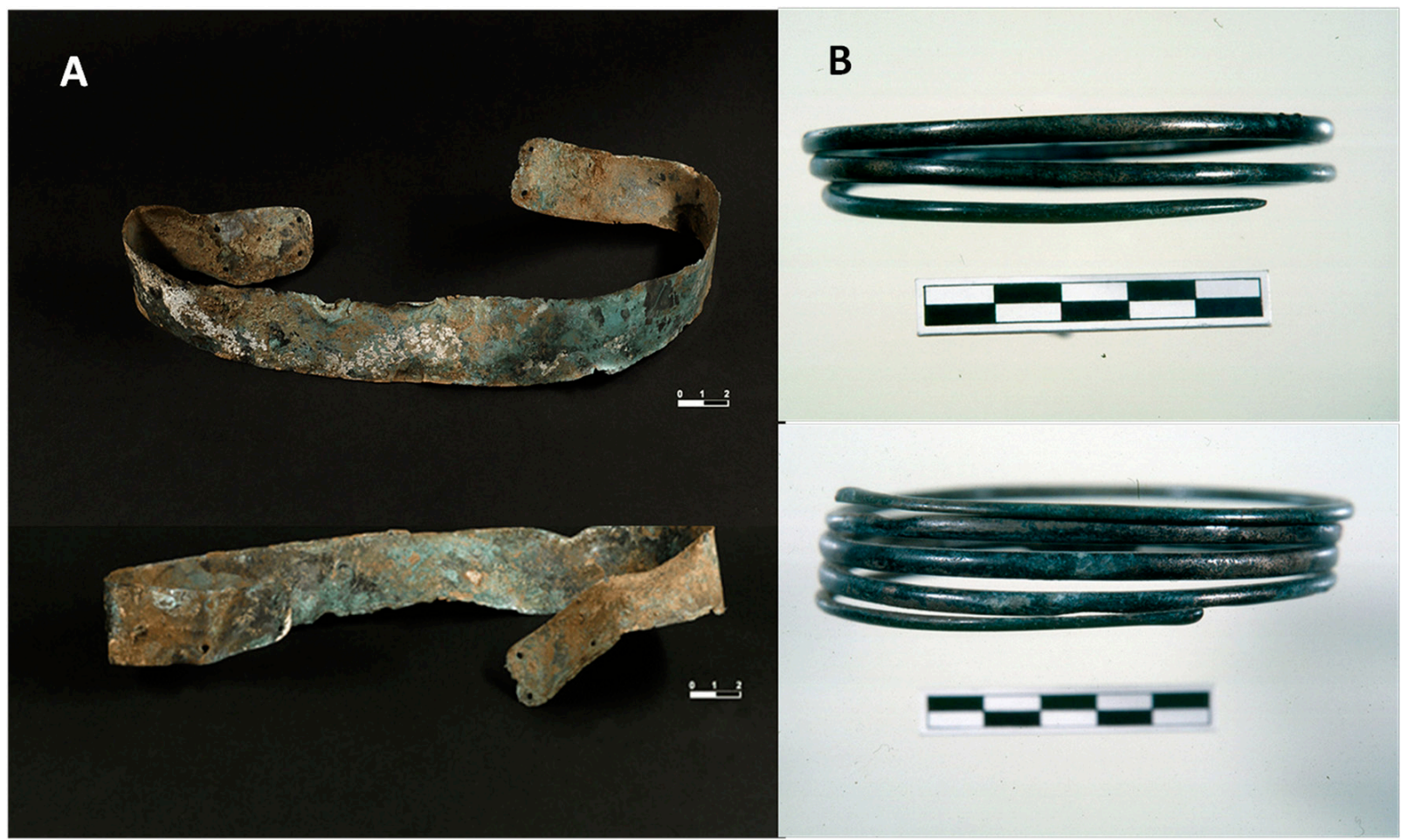

Fig. 4. Cova de Montanissell (Alt Urgell, Lleida): las piezas de ajuar más espectaculares vinculadas con las inhumaciones son una diadema y dos brazaletes en espiral de bronce. A. Lámina de bronce de $57,5 \times 4 \mathrm{~cm}$ sin paralelos en todo el noreste de la Península Ibérica; B. Brazaletes en espiral, conocidos en Europa continental y en el Mediterráneo desde los inicios del Bronce.

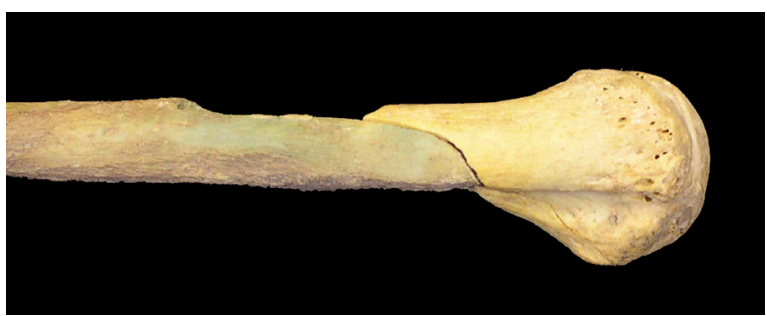

Fig. 5. Cova de Montanissell (Alt Urgell, Lleida): fractura perimortem a tercio proximal de húmero derecho del individuo de E1. La coloración diferenciada indica el contacto que tuvo la parte diafisaria con el ajuar de bronce.

bloque de piedra, los brazos cruzados a nivel torácico, la pierna derecha medio flexionada y la izquierda flexionada. Otras hipótesis compatibles resuelven que el cuerpo se mantuvo amortajado $\mathrm{o}$ atado en posición sentada o medio incorporada, apoyado dorsalmente en el bloque de piedra hasta su descomposición. La posición cruzada de los antebrazos puede reforzar esta posibilidad. Esta posición original podría explicar la mayor remoción esquelética de los restos.

E1 entierro E2 está situado en la parte más suroriental de la habitación sepulcral, en la zona de paso a su acceso actual, y alejado de las restantes inhumaciones. El esqueleto se encontró articulado con una preservación esquelética del $86 \%$. Es un niño de 7 años ( \pm 6 meses). Se le estima una estatura de $130 \mathrm{~cm}$.

Las alteraciones a nivel cortical aparecen en la parte inferior del esqueleto, ligeramente recubierta por una fina capa calcárea (Fig. 6A). Tienen la forma de porosidades compatibles con marcadores inespecíficos de estrés ambiental, como son las cribras orbitarias y del cuello de fémur (Fig. 6B). Es decir son alteraciones patológicas, no tafonómicas (Stuart-Macadam 1989; Campillo 1994; Isidro y Malgosa 2003). Se observaron fracturas recientes, afectando especialmente la región craneal.

En la exhumación los restos esqueléticos se hallaron articulados en decúbito supino, con una 

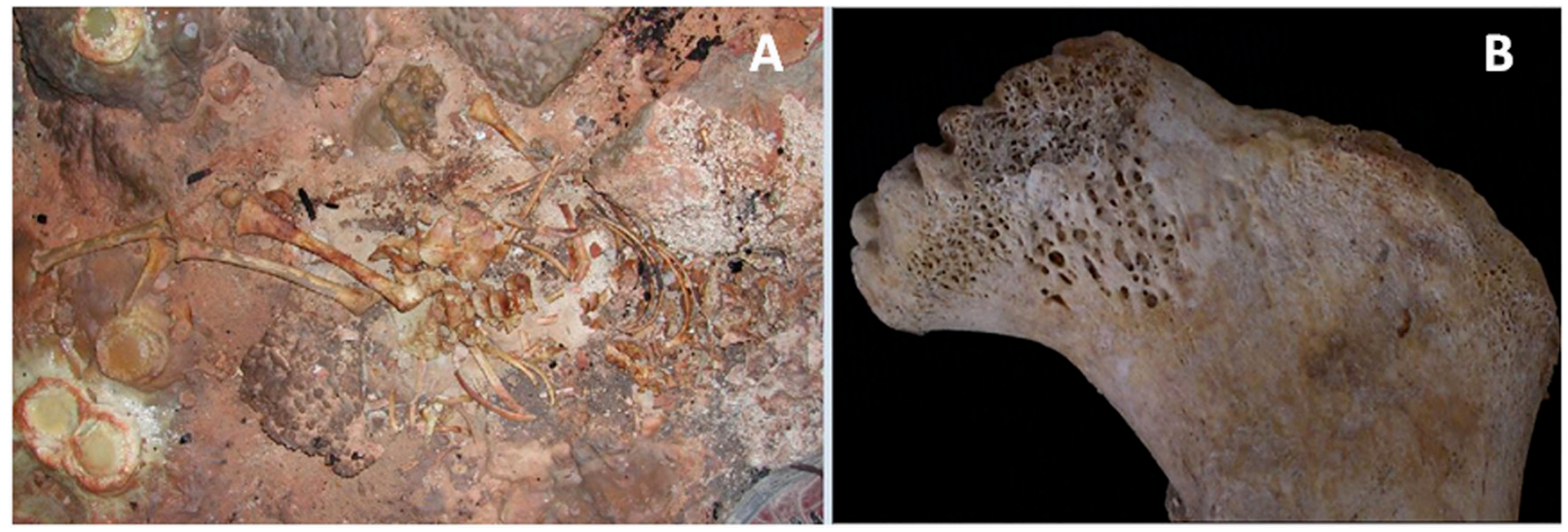

Fig. 6. Cova de Montanissell (Alt Urgell, Lleida): restos esqueléticos del individuo de E2. A. El cuerpo fue depositado en decúbito lateral derecho y extremidades inferiores en semi-flexión, situado en la parte más suroriental del espacio funerario; B. Detalle de la criba femoral a nivel del cuello femoral izquierdo. Ha sido habitual observar la presencia de cribas femorales en los individuos subadultos.

rotación derecha de la cintura escapular y pélvica y las extremidades superiores e inferiores en semiflexión. El brazo izquierdo y el antebrazo derecho estaban desplazados y la columna dorsal en parte desarticulada. El hallazgo de falanges, metacarpianos y piezas dentales, encima de una piedra situada a su derecha, indica que en origen el cuerpo fue depositado con la cabeza y las manos apoyados sobre ella (Fig. 6A). Esta posición explicaría los desplazamientos de las extremidades superiores y de otros conjuntos anatómicos relacionables con movimientos gravitacionales durante la reducción esquelética del cuerpo.

El entierro E5 se relaciona con la inhumación situada en la zona central de la habitación, muy cerca de E1. El esqueleto, sin articular, estaba preservado en un $86 \%$. Es una niña de 7 años ( \pm 6 meses) de edad. Se le estima una estatura de $130 \mathrm{~cm}$. Junto a ella también se recuperaron fragmentos de un vaso cerámico.

Como alteración cortical en el temporal derecho, la escápula derecha, la epífisis proximal del húmero derecho, las costillas derechas, la II falange distal de la mano derecha y el axis aparece una coloración verde intensa. También se observan alteraciones, en forma de porosidades, y que son compatibles con marcadores inespecíficos de estrés ambiental como las cribras orbitarias y del cuello del fémur, y las líneas de hipoplasia del esmalte dentario. Son alteraciones patológicas, no tafonómicas (Stuart-Macadam 1989; Campillo 1994; Isidro y Malgosa 2003).
Los restos se encontraron en un estado de fragmentación importante, afectando en especial la región craneal y los huesos largos de las extremidades. Entre estas se distingue una fractura antigua a nivel diafisario del fémur izquierdo es peri mortem de tipo espiroidal y trazo helicoidal. Sus características son muy similares a las descritas en el esqueleto E1: márgenes de fractura lisos y sin signos de regeneración ósea (Fig. 7). También en este caso, el traumatismo del fémur pudo estar relacionado con la causa o las circunstancias de la muerte. Las fracturas perimortem descritas de la mujer y la niña resultan de una fuerza de torsión como la que se podría producir en una caída, pero no por un golpe directo en la zona de fractura (Krenzer 2006).

Los restos esqueléticos se encontraron muy removidos y con articulación limitada a los dos coxales y las vértebras cervicales. No fue posible reconstruir la posición original de la niña en el espacio sepulcral. Probablemente los bloques de piedra cercanos a sus restos pudieron servir de apoyo a su cuerpo.

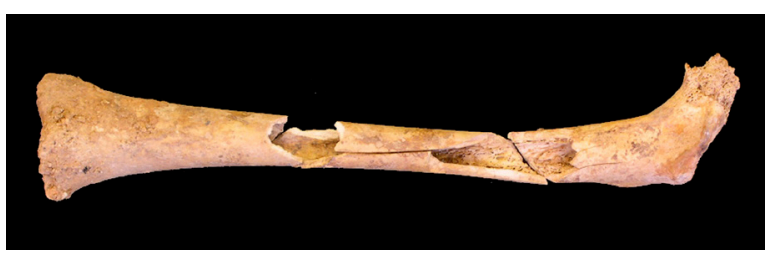

Fig. 7. Cova de Montanissell (Alt Urgell, Lleida): fractura perimortem de trazo helicoidal a diáfisis de fémur izquierdo del individuo de E5. 
El entierro E7 corresponde a la inhumación situada al norte de la habitación sepulcral: un esqueleto articulado de un varón adulto de 45-50 años de edad. La preservación esquelética es del $100 \%$. Se estima una talla de $160 \mathrm{~cm}$ y una constitución de robustez mediana. A nivel de cráneo se recuperó una aguja o punzón de hueso.

Una fina capa de calcita recubría algunos huesos de la parte superior del esqueleto (Fig. 8A). En el cráneo, junto al plano sagital de la pared externa del frontal, a $3 \mathrm{~cm}$ del bregma (Fig. 8B), se observó una cavidad ovalada de $15 \mathrm{~mm}$ de diámetro con los márgenes limpios y ondulados. La cavidad afecta a la tabla externa y presenta los márgenes regenerados. En la cara interna hay un pequeño orificio sin signos de remodelación ósea. La mayoría de las lesiones capaces de originar erosiones craneales son de etiología traumática y tumoral. La más plausible en este caso es un quiste dermoide exocraneal (Campillo 1977). A nivel del tercio proximal del húmero unas alteraciones líticas y bilaterales de la cortical son compatibles con lesiones no tafonómicas, relacionadas con el desarrollo de la musculatura del brazo. Otras anomalías de carácter patológico afectaron las vértebras cervicales y las extremidades inferiores y remiten a una patología osteoarticular degenerativa. Como patología bucal, destaca la malposición del incisivo lateral inferior derecho situado en la cara lingual de la mandíbula, y del canino inferior izquierdo, impactado en el cuerpo mandibular bajo el incisivo lateral inferior izquierdo. Se observó también la pérdida ante mortem del segundo premolar superior izquierdo, retroceso alveolar, cálculo dental e hipoplasia generalizada del esmalte.

Las fracturas antiguas y recientes son numerosas. Las primeras son claramente post mortem. Algunas están recubiertas por la capa de calcita, lo que refuerza su antigüedad.

Los restos esqueléticos estaban en articulación anatómica estricta o laxa coherente. La remoción de la región craneal fue reciente a juzgar por su impronta en el sedimento. Las articulaciones de la parte derecha del esqueleto, y la región lumbar y pélvica se mantienen de forma laxa. El esqueleto mostraba una posición en decúbito supino con rotación izquierda de las cinturas escapular y pélvica. La extremidad superior derecha reveló una flexión completa, mientras la izquierda estaba en semiflexión apoyándose en el bloque de piedra situado a la izquierda del varón. Las extremidades inferiores se hallaron en semiflexión.

El entierro E8 se relaciona con la inhumación situada en la zona suroccidental de la habitación, completamente recubierta por una capa de calcita (Fig. 9). El esqueleto es de una mujer joven de $20 \pm 1$ años. La robustez es mediana. La talla, baja, se estima en $147 \mathrm{~cm}$. Se le asocia un collar mixto de dentalia y cuentas tubulares de bronce. Su preservación es del $100 \%$.

Se han apreciado alteraciones de la cortical a nivel craneal, en la columna vertebral, en el fémur derecho y en el pie, que corresponden a alteraciones patológicas. En el parietal derecho, a nivel de
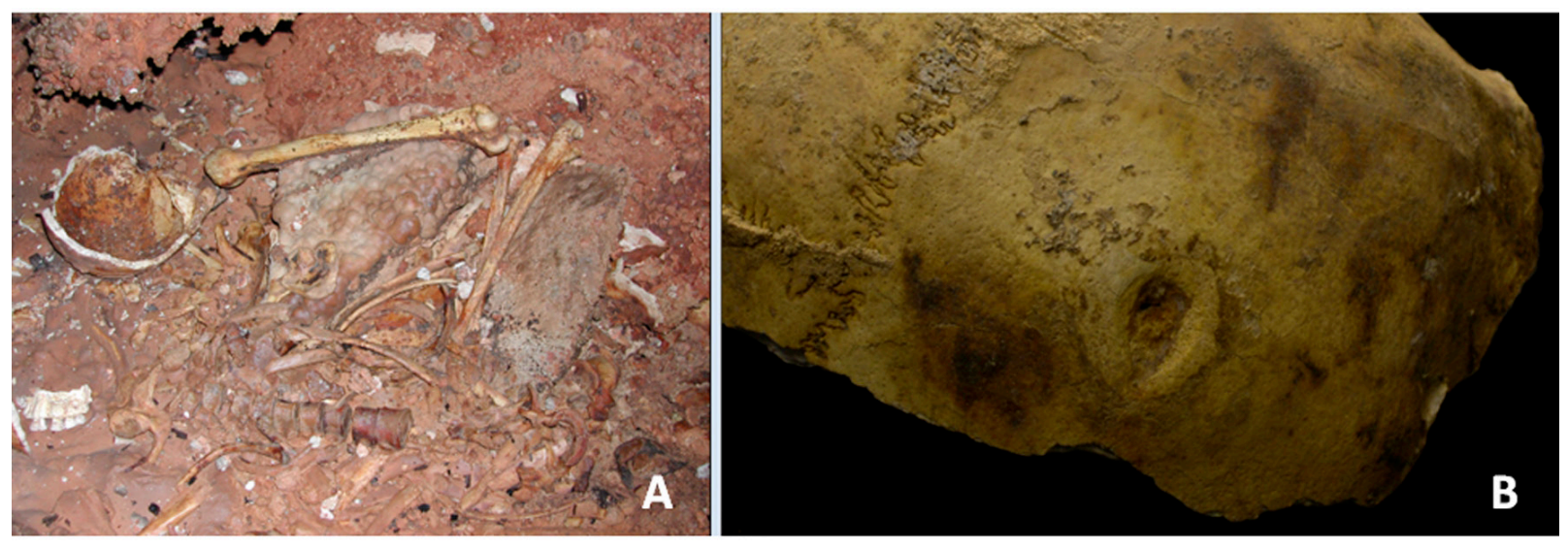

Fig. 8. Cova de Montanissell (Alt Urgell, Lleida): restos esqueléticos del individuo de E7. A. Detalle de la posición de la parte superior del esqueleto en decúbito supino y la extremidad superior izquierda en flexión, cerca del bloque de piedra; B. Alteración patológica a cráneo del individuo de E7. Se puede observar la depresión de forma ovalada, con un pequeño orificio que traviesa el díploe a la zona derecha del frontal.

Trab. prehist., 71, N. ${ }^{\circ}$ 1, enero-junio 2014, pp. 156-172, ISSN: 0082-5638

doi: $10.3989 /$ tp.2014.12130 


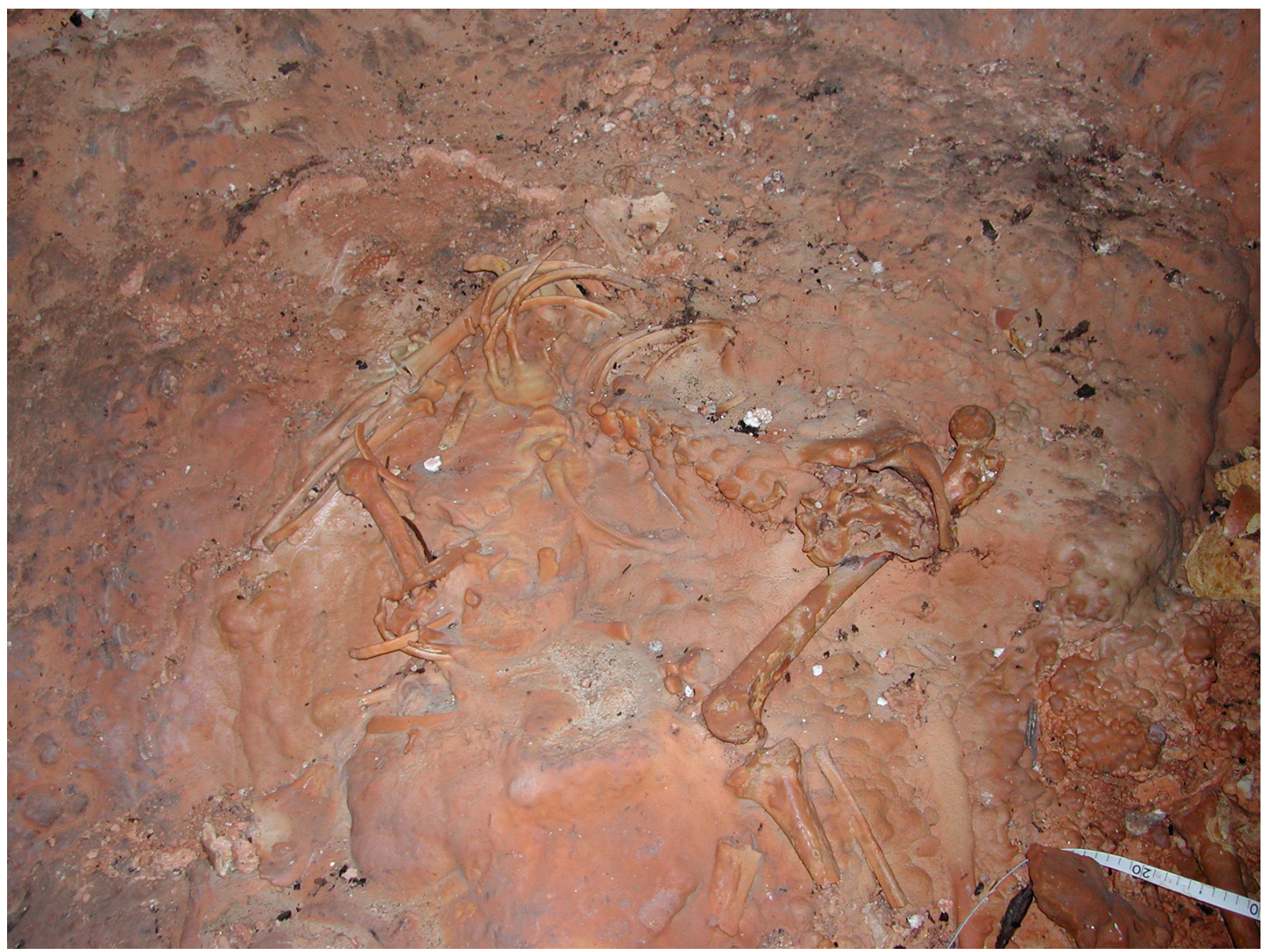

Fig. 9. Cova de Montanissell (Alt Urgell, Lleida): restos esqueléticos correspondientes al individuo de E8, con una posición anatómicamente muy forzada. Los restos están completamente fijados al suelo recubiertos por la capa calcárea.

la línea temporal superior y a $10 \mathrm{~mm}$ de la sutura coronal, se vió un crecimiento de $13 \mathrm{~mm}$ de diámetro anómalo y no tafonómico, compatible con un osteoma sésil con un círculo central de $55 \mathrm{~mm}$ más elevado y pigmentado. Los osteomas son neoplasias benignas, en general de dimensiones reducidas, y localizados frecuentemente en la bóveda craneana y sin sintomatología (Campillo 1977). Tenía una malformación congénita consistente en la hemi-sacralización derecha de la quinta vértebra lumbar. El fémur derecho presentaba una reacción perióstica focalizada, también patológica, en la cara posterior de la metáfisis distal, probablemente secundaria a una sobrecarga de esta zona. La articulación metafalángica de la I falange proximal del pie derecho mostraba una erosión compatible con una osteocondritis, lesión de etiología microtraumática. Como patología bu- cal, se advierte retroceso alveolar a nivel de premolares y molares inferiores derechos, e hipoplasia generalizada del esmalte dentario.

Las fracturas eran post mortem y su recubrimiento por la capa calcárea muestra que fueron previas a la deposición mineral. En el astrágalo izquierdo se identificó una "fractura de los pastores" en el margen posterior de la articulación subastragalina. El pequeño fragmento desprendido ante mortem no se volvió a unir al astrágalo y en el margen fracturado se observa una pseudoartrosis. El nombre de este defecto óseo se debe a su frecuencia entre individuos que caminan la mayor parte del tiempo por terrenos irregulares (Johnson et al. 1984; Nasser y Manoli 1990).

Los restos se hallaron en parte removidos, y en una posición anatómica muy forzada. El es- 
queleto estaba en decúbito prono, con el cráneo ligeramente apoyado sobre el macizo facial izquierdo, las extremidades derechas articuladas y la parte izquierda del cuerpo desplazada. La extremidad superior derecha se encontró en aducción de $90^{\circ}$ y extensión, cruzando por debajo el tronco, y la superior izquierda algo desplazada hacia el lado izquierdo del eje del cuerpo. La extremidad inferior derecha permaneció en aducción de $90^{\circ}$ y la rodilla en semiflexión, mientras los huesos de los pies se encontraron bajo los restos de E9, el esqueleto en posición perpendicular a E8. El coxal y el fémur izquierdo, completamente desplazados, se hallaron sobre los restos del entierro E9. La tibia estaba en la zona norte de la habitación sepulcral, a la altura de los restos de E11. El pie izquierdo, se halló junto al pie derecho articulado, también bajo los restos del individuo de E9 (Fig. 10).

La posición del esqueleto, inferida a partir de sus restos articulados, es muy forzada. Probablemente se deba a movimientos postdeposicionales del cadáver cuando no había completado la reducción esquelética y conservaba algunas partes blandas. Es muy posible que desde el depósito inicial hasta la intervención arqueológica, esta joven sufriera remociones en diferentes momentos. La reconstrucción de la posición original del cuerpo sugiere un decúbito lateral derecho con las extremidades inferiores en semiflexión. Un primer movimiento postdeposicional cuando aún mantenía tejidos blandos debió consistir en una rotación izquierda del eje del cuerpo, quedando en posición prona. Probablemente se produjeron otras remociones posteriores, en una fase de reducción esquelética total, y previas al depósito calcáreo. Los movimientos postdeposicionales de los restos de E8 podrían estar relacionados con la deposición de las inhumaciones posteriores de E9 o E10.

El entierro E9 corresponde a la inhumación situada en la zona occidental de la habitación sepulcral. Los restos están articulados y pertenecen a una joven de 14-15 años. El esqueleto es

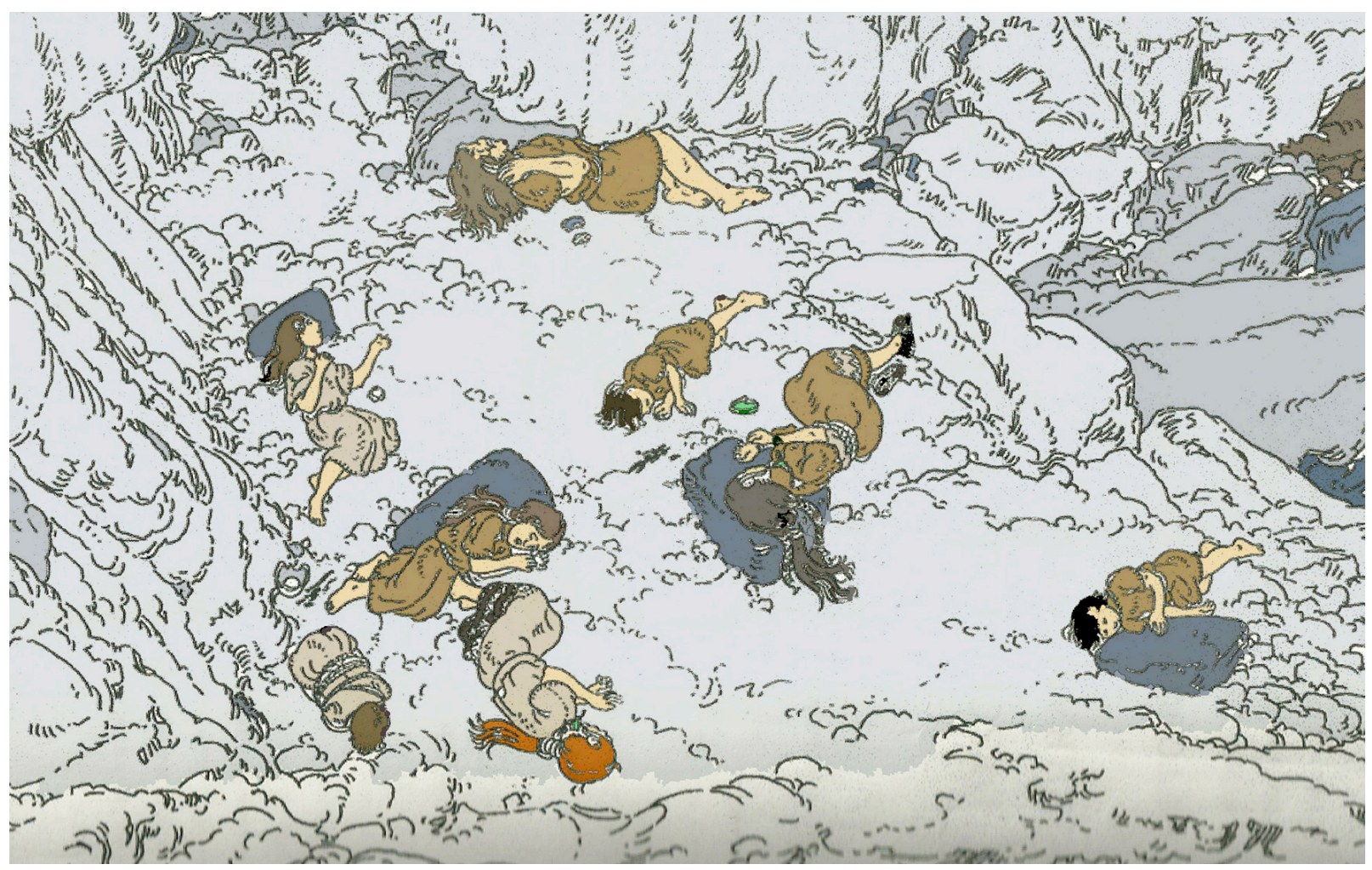

Fig. 10. Cova de Montanissell (Alt Urgell, Lleida): reconstrucción final de la escena y de la disposición de cada uno de los individuos estudiados (dibujo: Francesc Riart).

Trab. prehist., 71, N. ${ }^{\circ}$ 1, enero-junio 2014, pp. 156-172, ISSN: 0082-5638 doi: $10.3989 /$ tp. 2014.12130 
más bien robusto. Su preservación es del 100\%. En relación a este entierro se localizaron los restos de un vaso cerámico situado a nivel de los pies.

Una fina capa de calcita recubría casi todos los huesos del esqueleto. Hay alteraciones de carácter no tafonómico en algunos huesos de las extremidades superiores e inferiores. En los húmeros se advirtió una calcificación a nivel de la tuberosidad deltoidea. Se trata de una entesopatía relacionada con actividades repetitivas que implican esta zona muscular. A nivel del cóndilo lateral del fémur derecho una depresión redondeada que deja al descubierto el hueso subcondral es compatible con una osteocondritis dissecans. Esta alteración es producto de microtraumatismos de repetición que arrancan parte de la superficie articular. A nivel de la tuberosidad tibial de la misma pierna se advirtió una probable lesión de "Osgood-Schlatter", consecuencia del arrancamiento del tendón rotuliano por la tracción de los cuádriceps (Aufderheide y Rodríguez-Martín 1998; Ortner 2003). Esta lesión, que se da antes de la completa osificación del tercio proximal de la tibia (14 años), puede estar relacionada también con una sobrecarga. Esta puede explicar igualmente la reacción perióstica focal en el tercio proximal de la cara posterior de los peronés. Otras alteraciones de origen patológico inespecífico a nivel de la superficie cortical son las cribas femorales y las líneas de hipoplasia del esmalte dentario, habitualmente agrupadas con el nombre de marcadores de estrés (Stuart-Macadam 1989; Campillo 1994; Isidro y Malgosa 2003).

Se apreciaron fracturas post mortem antiguas a nivel craneal y mandibular recubiertas por la formación de una capa calcárea.

En la exhumación, los huesos, especialmente los de la parte derecha del cuerpo, estaban removidos y recubiertos por la capa de calcita, indicando que la remoción es antigua y anterior a la formación calcárea. Sin embargo la columna y las extremidades izquierdas se mantuvieron articuladas de forma estricta. Un fragmento proximal de cúbito derecho, el maxilar y la apófisis mastoides izquierdos se hallaron desplazados hacia la zona norte de la habitación. El fragmento de cúbito se localizó bajo el fémur izquierdo de E7, y la apófisis mastoides a nivel de las tibias. Bajo la cintura pélvica de los restos de E9 estaban los pies en conexión del individuo E8.
De las conexiones observadas se infiere que la joven se dispuso atravesada sobre los pies de E8, en decúbito lateral izquierdo, apoyada dorsalmente en la piedra situada a su espalda, con las extremidades superiores flexionadas, la derecha en aducción y la izquierda paralela al cuerpo y las extremidades inferiores en semiflexión. Los desplazamientos y las superposiciones óseas indican una probable secuencia temporal de inhumaciones, siendo el entierro de E9 posterior al de E8 y anterior al de E7.

El entierro E10 es la inhumación situada en la zona sureste de la habitación funeraria. Los restos esqueléticos están articulados y son de un subadulto de sexo indeterminado de $10 \pm 1$ años de edad El grado de preservación esquelética es del $95 \%$

La capa calcárea recubría casi todos los huesos, apareciendo en algunas zonas anatómicas como un depósito mineral muy grueso. Había alteraciones porosas de la cortical de carácter patológico en el techo de las órbitas, y líneas de hipoplasia generalizada del esmalte dentario. En la carilla superior articular izquierda del axis y en los cóndilos mandibulares presentaba una depresión redondeada compatible con osteocondritis. Son huellas de la patología micro-traumática. No se observaron fracturas.

Los restos se encontraron articulados en una posición anatómica muy forzada, en decúbito prono, con una flexión máxima de las extremidades superiores e inferiores a nivel de los codos, la cadera y las rodillas (Fig. 11). La posición de los restos sugiere que el cuerpo fue amortajado para conseguir y mantener esta posición de máxima flexión.

El entierro E11 es la inhumación situada en la zona noreste de la habitación funeraria. El esqueleto, articulado, es de una niña de $12 \pm 1$ años. La preservación esquelética es del 100\%.

Los restos esqueléticos están recubiertos por una capa calcárea tan gruesa que ha sido imposible separar las epífisis de los huesos largos y algunos cuerpos vertebrales del bloque de espeleotema (Fig. 12). Se han observado alteraciones en forma de reacción perióstica bilateral estriada y fina a nivel de la metáfisis distal de fémur, de probable etiología microtraumática. Entre las lesiones de origen inespecífico están las cribas orbitarias bilaterales y las líneas de hipoplasia del esmalte dentario (Hengen 1971). 


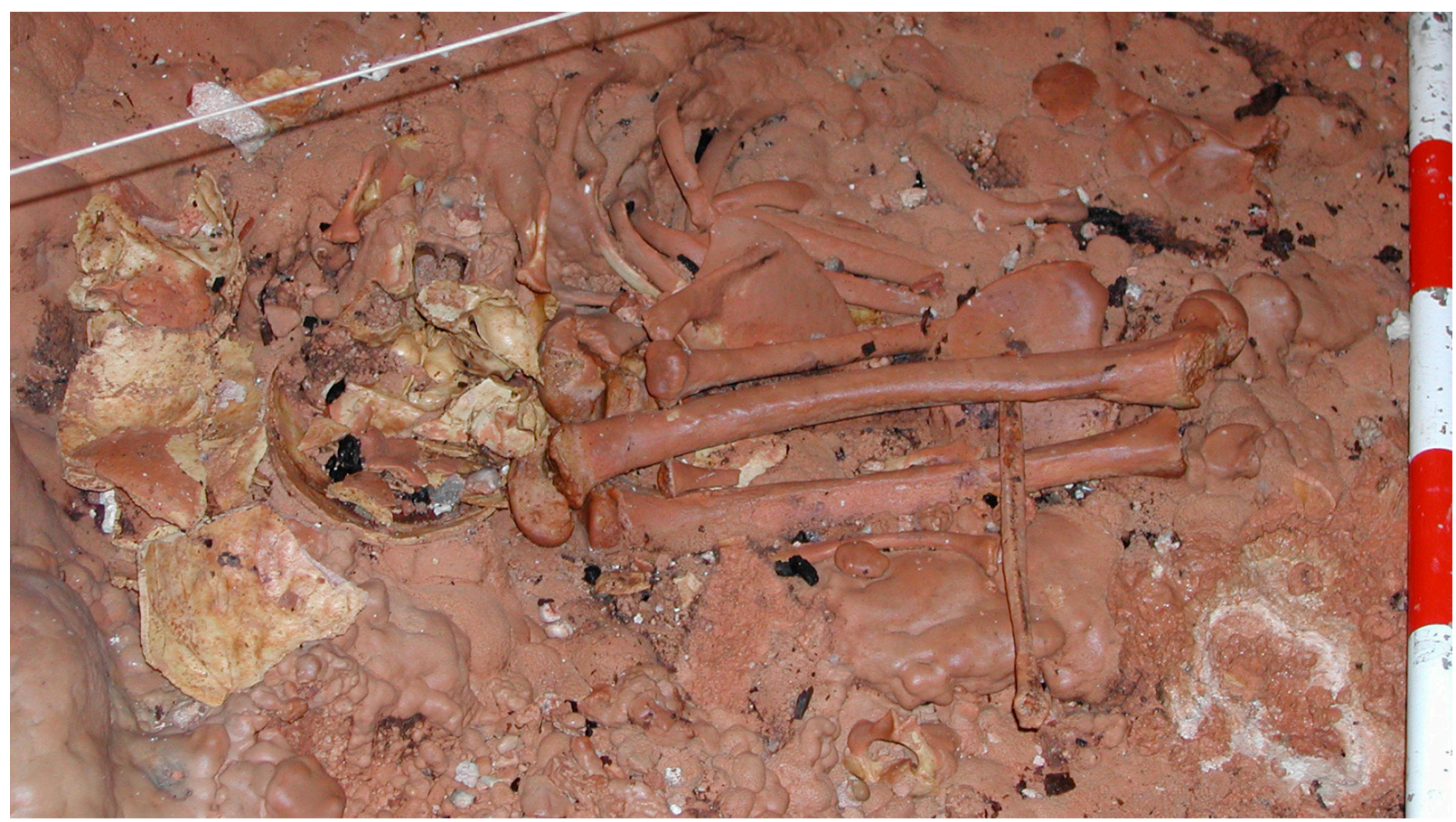

Fig. 11. Cova de Montanissell (Alt Urgell, Lleida): restos esqueléticos correspondientes al individuo de E10, en decúbito prono con flexión máxima de extremidades superiores e inferiores.

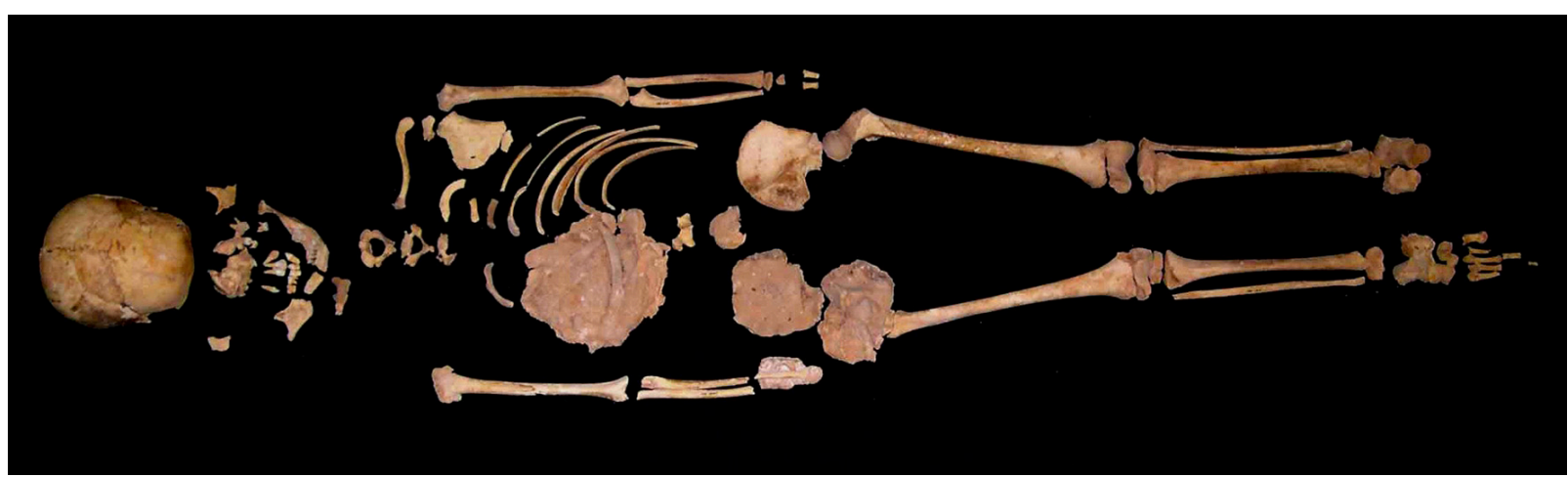

Fig. 12. Cova de Montanissell (Alt Urgell, Lleida): reconstrucción en el laboratorio de los restos del individuo de E11. A pesar de que se ha retirado la capa calcárea de prácticamente todo el esqueleto, algunos elementos (costillas, coxal, y antebrazo derechos) no han podido separarse del bloque de espeleotema.

En la exhumación solo se observaron ligeras desarticulaciones a nivel de la mandíbula, el fémur derecho, o la parte dorsal de la columna vertebral. En origen el cuerpo estaría articulado en decúbito supino, con una ligera rotación izquierda de la cintura escapular. El brazo derecho se encontraba en paralelo al cuerpo, con flexión máxima de antebrazo, y el izquierdo en semiflexión sobre el cuerpo. Las extremidades inferiores también estaban semiflexionadas.

\section{HISTORIA TAFONÓMICA DEL CONJUNTO}

En la cueva de Montanisell se exhumaron los restos de 8 individuos que compartían un mismo espacio sepulcral, en una recóndita habitación de una de las galerías. Los esqueletos tenían buenos porcentajes de preservación, y en general buena conexión anatómica, aunque conservada de forma laxa. Estos aspectos permitieron identificar el 
carácter primario de las inhumaciones (Armentano y Malgosa 2003) que ocuparon toda la zona funeraria respetando en general el espacio e integridad de cada una de ellas, ya que no se observan remociones ni arrinconamientos de huesos. Los individuos fueron depositados mayoritariamente en decúbito supino, con una ligera rotación de cintura escapular y pélvica, o también en decúbito lateral, y siempre con las extremidades superiores e inferiores semiflexionadas. La orientación probablemente estuvo en función del espacio asignado a cada inhumación. Se observó una relación entre la posición de los individuos y los grandes bloques de piedra, así como entre el ajuar de bronce y los individuos femeninos E1, E8. La coloración verde que presentan algunos elementos esqueléticos de E1 y del cercano E5 se justifica por la oxidación de los elementos de bronce.

Es notable la disposición diferenciada del individuo infantil de la E10, en posición prona y completamente plegado. Este aspecto indica que fue amortajado para mantener esta posición anatómicamente tan forzada. Otros yacimientos con este tipo de inhumaciones (Armentano et al. 2012) confirman que la postura se utilizó durante la Prehistoria reciente para enterrar y/o transportar a los muertos. En este caso no se observaron caracteres antropológicos especiales que sugirieran una práctica funeraria diferenciada para este individuo.

Las alteraciones a nivel de la cortical corresponden a dos tipologías principales: tafononómicas, la formación calcárea de una capa de espeleotema, y no tafonómicas, las alteraciones patológicas que caracterizan el grupo. El espeleotema se debe al efecto aerosol que provoca la humedad y la filtración de aguas. Puede formarse en un espacio de tiempo corto, sin exigir grandes cambios climáticos o alteraciones de la temperatura (Armentano et al. 2006). Esta capa mantuvo la conexión anatómica de los individuos, y permitió reconocer las características articulares de los restos cuya descomposición tuvo lugar sin sedimento ni cubrimiento alguno. La ausencia de fauna carroñera y la presencia de esta capa justifican la buena continuidad anatómica de los individuos y el mantenimiento estricto de algunas de las articulaciones. Además sugieren que la cueva estaba cerrada o era poco accesible al paso de la fauna al interior.

Las alteraciones patológicas son anomalías frecuentes en el registro antropológico antiguo (periostitis, osteocondritis, lesiones entesopáticas, tumoraciones, etc.), pero destaca el elevado número de lesiones. El hecho de que los restos nunca hayan estado enterrados, ni expuestos a la intemperie, ha favorecido probablemente su buen estado de conservación que, a su vez, ha facilitado la observación y el examen externo. Los incluidos, en un momento de su historia postmortem, bajo la capa de calcita han conservado mejor si cabe, su aspecto y su superficie cortical.

El efecto tafonómico más importante del registro de la Cova de Montanissell ha sido, sin duda, la alteración en forma de desplazamientos y movimientos óseos. El estudio detallado de la posición de los esqueletos, así como la distribución espacial de los diferentes elementos óseos, sugieren que los individuos fueron depositados cuidadosamente en este espacio de forma sucesiva durante un período de tiempo no muy largo. Este rango cronológico comprende un mínimo de unos pocos años a partir del análisis tafonómico, y un máximo de 100 a partir de las dataciones de $\mathrm{C} 14$. Se han interpretado como 8 inhumaciones primarias sucesivas, pero no se descarta que algunas fueran simultáneas, por ejemplo los dos enterramientos centrales, E1 y E5.

Los primeros cadáveres depositados no se apartaron ni se arrinconaron con las nuevas inhumaciones. Las evidencias de movimientos puntuales de restos son explicables en el curso de una práctica funeraria de inhumación sucesiva. El proceso postdeposicional que afectó significativamente a los esqueletos fue la reutilización del espacio sepulcral durante su funcionamiento como cementerio. Los pocos huesos hallados sin conexión anatómica y desplazados indican que el lapso temporal entre dos enterramientos sucesivos fue suficiente para una reducción esquelética parcial del cadáver anterior. El tiempo necesario para conseguir la total descomposición cadavérica varía mucho en función de variables que aceleran o retrasan el proceso de putrefacción (Haglund y Sorg 1997). Algunas de ellas son la causa de la muerte, el estado de nutrición del individuo antes de morir, las sustancias ingeridas, las prendas que lo cubren, la temperatura exterior, la humedad en torno al cadáver, la estación del año en que se efectúa la inhumación, las influencias atmosféricas y la acción de los insectos necrófagos, entre otras. Parece que en una cueva cárstica, con un elevado grado de humedad, la descomposición de los tejidos blan- 
dos sería notable en pocos meses (DiMaio y DiMaio 2001).

Los efectos tafonómicos no antrópicos, y posteriores al período de uso de la Cova de Montanissell como espacio sepulcral, como la formación calcárea de espeleotema que afecta sobre todo la zona oeste de la habitación, las corrientes de agua o la acción eventual de fauna, etc. no fueron suficientemente importantes ni capaces de alterar de forma significativa la posición original de los individuos. Los movimientos y fracturas post mortem recientes identificadas corresponden sin duda al descubrimiento de la cavidad: están concentradas en la zona de acceso actual al espacio sepulcral y afectan al entierro central de la mujer adulta que tenía el ajuar más relevante.

Los efectos tafonómicos en forma de fracturas también confirman la manipulación vinculada con la reutilización del espacio sepulcral para inhumaciones sucesivas. Se distinguieron casos de fractura post mortem y en la mujer E1 y la niña E5 fracturas peri mortem que pudieron estar vinculados con la causa o las circunstancias de su muerte.

Se ha elaborado dos secuencias hipotéticas de deposición de los 8 cadáveres a partir de los datos tafonómicos y considerando que el grado de conexión anatómica de las primeras inhumaciones debería ser menor que el de las posteriores. En la primera secuencia la mujer E1 y la niña E5, especialmente distinguidas por su ajuar, habrían protagonizado un entierro, cuya posición inicial en la serie se justifica por su mayor remoción esquelética. A su alrededor se depositaron otras tres personas que, según la superposición de elementos esqueléticos, fueron primero la mujer joven E8, después la joven de 14 años E9 y, por último, el hombre adulto E7. Parece lógico pensar que los entierros del probable niño E10 y la niña E11 (10 y 12 años respectivamente) fueron posteriores a la mujer joven de E8, cuya posición más forzada, sería resultado de las perturbaciones y remociones debidas al paso de nuevos entierros.

La segunda hipótesis propone como primeros enterramientos los de la parte más occidental de la habitación sepulcral, que habrían mantenido mejor la posición original del esqueleto gracias a que la capa de espeleotemas los cubrió y protegió a lo largo del tiempo. La secuencia lógica entonces se iniciaría con el entierro de E8, o E10, seguido por el de E9 o E11, los de E1 y E5, finalizando con los de E2 y E7 (Fig. 12).
Ambas secuencias son compatibles con la hipótesis de un enterramiento colectivo y con la de inhumaciones primarias sucesivas. Tampoco se descarta que algunas inhumaciones, como las de la mujer E1 y la niña E5, hubiesen sido simultáneas. El que ambas presenten fracturas peri mortem, vinculables con eventos accidentales vitales puede reforzar esta hipótesis. La historia post mortem de cada persona se resume, primero, en su propia descomposición, después en la eventual alteración provocada o no por una nueva inhumación y, por último, en la formación calcárea que afectó gran parte de los restos.

Este estudio antropológico, integrando el estudio tafonómico y genético, junto con las dataciones radiométricas y datos arqueológicos, ha permitido esbozar el panorama de la secuencia de enterramientos que realizó este grupo de hombres y mujeres en la Edad del Bronce. Sin duda este estudio holístico ha ofrecido una imagen muy distinta a la que previamente aparecía como la más probable: el enterramiento simultáneo de los integrantes de una familia después de algún tipo de catástrofe. El análisis de la intencionalidad o no de las posiciones de los enterrados, la sucesión de los entierros, el estudio de lesiones óseas y el grado de parentesco entre los enterrados, ha mostrado un grupo que repetidamente y durante años enterraron a sus seres queridos en la cueva.

En resumen, la reconstrucción de la historia tafonómica de los restos indica que, en un corto espacio de tiempo fijado por 8 dataciones radiocarbónicas entre el 3200 y el 3300 BP, parte de la Cova de Montanissell se utilizó para enterrar sucesivamente 8 personas de, al menos, 5 linajes maternos distintos (ADN mitocondrial). Probablemente los difuntos fueron atados o amortajados para poder ser transportados hasta la habitación sepulcral. Allí fueron colocados en semiflexión en un rincón determinado, acompañados de sus ajuares. Cuando el grupo volvía a la cavidad para enterrar a otro miembro de la comunidad, pudieron, a propósito o no, tocar alguna parte anatómica o desplazar el cuerpo. Los cadáveres en fase de reducción esquelética pudieron perder la conexión de algún elemento óseo, mientras que los que mantenían parte de tejido blando, con la manipulación, adoptaron una posición más forzada. Cuando la cueva dejó de usarse, una formación de calcita recubrió los restos fijando la escena durante siglos. La primavera de 2004 un equipo de bomberos aficionados a 
la espeleología iluminó una vez más la habitación.

\section{AGRADECIMIENTOS}

Este trabajo ha sido subvencionado parcialmente por el Area de Coneixement i Recerca y el proyecto 2009SGR566, ambos de la Generalitat de Catalunya. Queremos agradecer a J.M. Puche y F. Riart las imágenes interpretativas de los enterramientos y al equipo arqueológico su contribución en el estudio.

\section{BIBLIOGRAFÍA}

Alduc-Le Bagouse, A. 1988: "Estimation de l'âge des non-adultes: maturation dentaire et croissance osseuse. Données comparatives pour deux nécropoles médiévales bas-normandes". En Actes des 3èmes Journées Anthropologiques. Notes et Monographies Techniques 24, Éditions du Centre National de la Recherche Scientifique. París: 81-103.

Aguirre, E. 1997: "La tafonomía como ciencia: aspectos epistemológicos". Journal of Iberian Geology 23: 37-52.

Armentano, N.; Esteve, X.; Nociarová, D. y Malgosa, A. 2012: "Taphonomical study of the anthropological remains from Cova des Pas (Minorca)". Quaternary International 275: 112-119.

Armentano, N.; Gallart, J.; Jordana, X.; López, J. B. y Malgosa, A: 2008. "La Cova sepulcral de Montanissell (Sallent-Coll de Nargó, Alt Urgell): pràctiques funeràries singulars durant l'edat del bronze al Prepirineu". En $1^{\text {er }}$ Col-loqui d'Arqueologia d'Odèn (Solsonès 2006). La prehistòria avui en el Prepirineu lleidatà: 55-72. Solsona.

Armentano, N.; Gallart, J.; Jordana, X.; López, J. B.; Malgosa, A.; Rafel, N. 2006: "La Cova sepulcral de Montanissell (Sallent-Coll de Nargó, Alt Urgell): pràctiques funeràries singulars durant l'edat del bronze al Prepirineu". Tribuna d'Arqueologia: 141-167.

Armentano, N. y Malgosa, A: 2003. "Enterramientos primarios versus enterramientos secundarios". En M. P. Aluja, A. Malgosa y R. Nogués (eds.): $A n-$ tropología y Biodiversidad. Bellaterra Edicions I. Barcelona: 39-49.

Aufderheide A y Rodríguez-Martín C. 1998: The Cambridge Encyclopedia of Human Paleopathology. Cambridge University Press. Cambridge.

Behrensmeyer, A. K. 1978: "Taphonomic and ecologic information from bone weathering". Paleobiology 4: 150-162.
Brothwell, D. R. 1987: Desenterrando huesos. Fondo de Cultura Económica. Madrid.

Campillo, D. 1994: Paleopatología. Los primeros vestigios de la enfermedad I. Fundación Uriach 1838. Barcelona.

Campillo, D. 1977: Paleopatología del cráneo en Cataluña, Valencia y Baleares. Montblanc-Martín. Barcelona.

Chimenos, E.; Safont, S.; Alesán, A.; Alfonso, J. y Malgosa, A. 1999: "Propuesta de protocolo de valoración de parámetros en Paleodontología". Gaceta Dental 102: 44-52.

Cretot, M. 1978: L'arcade dentaire humaine (Morphologie). Julien Prélat. Paris.

Duday, H. 2009: The Archaeology of the Death. Lectures in Archaeothanatology. Oxbow Books. Oxford.

Duday, H.; Cortaud, P.; Crubezy, E.; Sellier, P. y Tillier, A. M. 1990: "L'anthropologie de terrain. Reconnaissance et interprétation des gestes funéraires". Bulletin et mémoires de la Société d'Anthropologie de Paris 2, 3-4: 29-50.

DiMaio, V. y DiMaio, D. 2001: Forensic Pathology. CRC Press. Boca Ratón.

Ferembach, D.; Schwidetzky, I. y Stloukal, M. 1980: "Recommendations for Age and Sex Diagnoses of Skeletons". Journal of Human Evolution 9: 517549.

Gifford-Gonzalez, D. 1991: "Bones are not enough: analogues, knowledge, and interpretive strategies in zooarchaeology". Journal of Anthropological Archaeology 10: 215-254.

Gilbert, B. M. y McKern, T. W. 1973: "A method for aging the female Oos pubis". American Journal of Physical Anthropology 38: 31-38.

Haglund, W. D. y Sorg, M. H. 1997: "Introduction to forensic taphonomy". En W. D. Haglund y M. H. Sorg (eds.): Forensic Taphonomy. The Postmortem Fate of Human Remains. CRC Press. Boca Raton: 1-9.

Hengen, O. P. 1971: "Criba orbitalia: pathogenesis and probable etiology". Homo 22: 57-75.

Isçan, M. Y.; Loth, S. R. y Wright, R. K. 1984: "Metamorphosis at the sternal rib end: A new Method to Estimate Age at Death in White Males". American Journal of Physical Anthropology 65: 147-156.

Isidro, A. y Malgosa, M. 2003: Paleopatología. La enfermedad no escrita. Masson. Barcelona.

Johnson, E. 1985: "Current developments in bone technology". En M. Schiffer (ed.): Advances in archaeological method and theory 8, Academic Press. New York: 157-235.

Johnson, R. P.; Collier, B. D. y Carrera, G. F. 1984: "The Os Trigonum Syndrome: Use of Bone Scan in the Diagnosis". Journal of Trauma-Injury Infection \& Critical Care 24(8): 761-764.

Jordana, X.; Galtés, I.; Turbat, T.; Batsukh, D.; García, C.; Isidro, A.; Giscard, P. H. y Malgosa, A. 2009: 
"The warriors of the steppes: osteological evidence of warfare and violence from Pazyryk tumuli in the Mongolian Altai”. Journal of Archaeological Science 36: 1319-1327.

Kanz, F. y Grossschmidt, K. 2006: "Head injuries of Roman Gladiators". Forensic Science International 160: 207-216.

Krenzer, U. 2006: Compendio de métodos antropológico forenses para la reconstrucción del perfil osteo-biológico VIII. Centro de análisis forenses y ciencias aplicadas. Guatemala.

Krogman, W. M. y Isçan, Y. M. 1986: The Human Skeleton in Forensic Medicine. Ch. C. Thomas Publisher LTD. Springfield.

López, J. B.; Malgosa, A.; Gallart, J. y Rafel, N. 2005: "Cova de Montanissell (Sallent- Coll de Nargó, Alt Urgell). Operació: 'Senyora de les muntanyes"'. Cota Zero 20: 27-39.

Lovejoy, C. O.; Meindl, R. S.; Pryzbeck, T. R. y Mensforth, R. P. 1985: "Chronical Metamorphosis of the Auricular Surface of the Ilium: A New Method for the Determination of Adult Skeletal Age at Death". American Journal of Physical Anthropology 68: 1528.

Lyman, R. 1994: Vertebrate taphonomy. Cambridge manuals in archaeology. Cambridge University Press. Cambridge.

McKern, T. W. y Stewart, T. D. 1957: Skeletal age changes in Young American males. Quartermaster Research and Development Comand Technichal Report EP-45. Natick, Massachusetts.

Nasser S. y Manoli A. 1990: "Fracture of the Entire Posterior Process of the Talus: A Case Report". Foot \& Ankle International 10 (4): 235-238.

Nawrocki, S. P. 1995: "Taphonomic process in historic cemeteries". En A. Grauer (ed.): Bodies of evidence: Reconstructing History through Skeletal Remains. Wiley-Liss. New York: 49-68.

Olivier, G. 1960: Pratique Anthropologique. Vigot frères. París.

Ortner, D. J. 2003: Identification of Pathological Conditions in Human Skeletal Remains. Academic Press. New York.

Reverte, J. M. 1991: Antropología forense. Ministerio de Justicia, Secretaria general Técnica. Madrid.

Roberts, C. A. y Manchester, K. 2005: Archaeology of disease. Sutton Publishing Ltd. Stroud.

Sauer N. J. 1998: "The Timing of injuries and manner of death. Distinguishing among antemortem, peri- mortem and postmortem trauma". En K. J. Reichs (ed.): Forensic Osteology. Advances in the Identification of Human Remains. Charles C. Thomas. Springfield: $321-332$.

Scheuer, L. y Black, S. 2000: Developmental Juvenile Osteology. Academic Press. London.

Schutkowski, H. 1993: "Sex Determination of Infant and Juvenile Skeletons. I. Morphognostic Features". American Journal of Physical Anthropology 90(2): 199-205.

Shipman, P. 1981: Life History of a Fossil. Harvard University Press. Cambridge.

Simón, M.; Jordana, X.; Armentano, N.; Santos, C.; Díaz, N.; Solórzano, E.; López, J. B.; GonzálezRuiz, M. y Malgosa, A. 2011: "The presence of nuclear families in prehistoric collective burials revisited: the bronze age burial of Muntanissell Cave (Spain) in the light of aDNA". American Journal of Physical Anthropology 146(3): 406-13.

Stuart-Macadam, P. 1989: "Nutritional deficiency diseases”. En M. Y. Isçan y K. A. R. Kennedy (eds.): Reconstruction of life from the skeleton. Alan, R. Liss. Nueva York: 201-202.

Todd, T. W. 1920: "Age changes in the pubic bone: I. The white male pubis". American Journal of Physical Anthropology 3: 467-470.

Trotter, M. y Glesser, G. C. 1952: "Estimation of stature from long bones of American whites and Negroes". American Journal of Physical Anthropology 10: 463-514.

Tung, T. A. 2007: "Trauma and violence in the Wari empire of the Peruvian Andes: warfare raids, and ritual fights". American Journal of Physical Anthropology 133: 941-956.

Ubelaker, D. H. 1989: Human Skeletal Remains. Excavation analysis, interpretation. Taraxacum. Washington, D.C.

Vallois, H. V. 1960: "Vital statistics in prehistoric populations as determined from archaeological data". En R. F. Heizer y S. F. Cook (eds.): The Application of Quantitative methods in archaeology 28, Chicago Press. Chicago: 186-222.

Walker, P. L. 2001: "A bioarchaeological perspective on the history of violence". Annual Review of Anthropology 30: 573-596.

Walker, P. L.; Johnson, J. R. y Lambert, P. M. 1988: "Age and sex biases in the preservation of human skeletal remains". American Journal of Physical Anthropology 76: 183-188. 